\title{
Different kinds of consumer response to the reward recycling technique: similarities at the desired routine level
}

Different kinds of consumer response

\author{
Gonzalo Díaz Meneses and Asunción Beerli Palacio \\ Universidad de Las Palmas de Gran Canaria, The Canary Islands, Spain
}

\begin{abstract}
Purpose - The objective of this research is not only to provide a new theoretical framework to overcome doctrinal inconsistencies related to the reward recycling technique but also to empirically contrast the proposed explanations.

Design/methodology/approach - This research follows a quasi-experimental design. This type of treatment comprises the application of a draw-based prize technique. A questionnaire was issued to gather the information from a sample with 123 individuals. The approach is quantitative.

Findings - It was found that recycling behaviour has become a routine or habit with recognized awareness of ecology and recycling, but without a high level of involvement, since today's adoption process does not require such effort. This implies that the efficacy of the reward technique has been transformed and consequently its effects must be understood differently. To be specific, responders and non-responders are similar, in terms of their levels of beliefs about recycling, ecological concern and involvement with recycling, and both show the same model of adoption with a low hierarchy of effect and with a few minor differences. Nevertheless there is only one difference between sustainers and non-sustainers, namely, the sustainers' greater ecological concern before the promotion application.
\end{abstract}

Research limitations/implications - The non-existence of a control group is a limitation with the result that the validity of the experiment is not being totally checked.

Originality/value - This research provides some empirical evidence challenging some old presumptions concerning the understanding of recycling.

Keywords Social marketing, Recycling, Promotion

Paper type Research paper

\section{Introduction}

The classic recycling behaviour theory proposes that before adopting the desired recycling conduct, a consumer will have processed a huge amount of information about both the deterioration of nature and about how to recycle. This so called high involvement model, or classic paradigm, assumes not only that consumers are active participants in the process of gathering information about ecology and recycling but also that the immediate consequence is that they form a favourable attitude toward recycling. The final result is the making of a high commitment decision to recycle as explained by the theories of multiple attributes and reasoned action (Kok and Siero, 1985; Goldenhar and Connell, 1993; Taylor and Todd, 1995; Kalafatis et al., 1999).

However, this predominant paradigm recognizes the existence of an exception when explaining the recycling reward technique. In fact, one of the most accepted propositions of how consumers were thought to process information and react to recycling reward techniques was that those who respond show little interest in recycling (Katzev and Pardini, 1987; Vining and Ebreo, 1989; Wesley et al., 1995).

Asia Pacific Journal of Marketing
and Logistics
Vol. 18 No. 1, 2006
pp. 43-60
C Emerald Group Publishing Limited
$1355-5855$ DOI 10.1108/13555850610641082 
APJML 18,1
Nevertheless, it seems hard to match the evidence that the reward reinforcement is one of the most effective promotion techniques (Geller et al., 1975; Witmer and Geller, 1976; Luyben and Bailey, 1979; Hamad et al., 1980; Vining and Ebreo, 1990; Needleman and Geller, 1992) with the fact that recycling behaviour is high involvement, as indicated by the classic paradigm. Perhaps this paradox in environmental literature is rooted in the fact that this low involvement effect of recycling behaviour has been purely theoretical, with no empirical study having been carried out to date (Thogersen, 1994a,b).

On the other hand, although this particular technique has proved to be highly effective, many authors have expressed concern about its limited capacity to maintain the desired conduct once the reinforcement is removed, i.e. raffles or draws (Witmer and Geller, 1976; Luyben and Cummings, 1981). The predominant paradigm makes it clear that this limitation is due to there being no change in consumers' internal components after the application of the reward promotion technique (Hopper and Nielsen, 1991; Leeming et al., 1993; Wesley et al., 1995; Shrum et al., 1994). This would therefore appear to infer that when the reward technique achieves long-lasting effects on recycling behaviour, this occurs as a result of certain changes taking place in the consumer's psychological core. Nevertheless, the classic approach does not consider that recycling behaviour is no longer a novelty and that the reinforcement effect is now working at the tail end of the innovation diffusion process. In this advanced phase of adoption, it seems unlikely that responders are reluctant to recycle since recycling is widely accepted in society, and even after the promotion is withdrawn they will continue recycling because their knowledge and evaluations of recycling have considerably increased.

In order to clarify these apparent contradictions, the objective of this research is not only to provide a new theoretical framework to overcome doctrinal inconsistencies but also to empirically contrast the proposed explanations. To accomplish these aims, it is necessary to analyse the differences between responders and non-responders in this particular promotional technique and to examine the discrepancies between sustainers and non-sustainers.

\section{Review of existing literature}

From today's perspective, modern recycling behavior would appear to have commenced in the seventies, when households were exhorted to save paper, cardboard, metals and other materials in an attempt to combat the energy crisis (Ackerman, 1997). The recycling drive involved not only a general urge to take action and reduce wastefulness, but also more specific reactions to the spread of litter, and to the threat of pollution from landfills. Hence, it seemed logical to assume that recycling was not only a high involvement form of behavior but also that there would be many differences between recyclers and non-recyclers (Lansana, 1992).

Thus, the predominant paradigm in environmental literature highlights the idea that recycling behaviour is a high commitment conduct since it is considered an environmental conduct (Kok and Siero, 1985; Goldenhar and Connell, 1993; Taylor and Todd, 1995; Kalafatis et al., 1999). In addition, the predominant environmental literature emphasises the idea that individuals who are reluctant to recycle, or who neither recognize the importance of, nor express interest in, recycling waste are the same individuals who are most interested in extrinsic stimuli such as prizes, gifts and financial rewards (Vining and Ebreo, 1990; Oskamp et al., 1991; Dahle and Neumayer, 2001). This consumers' focus on external reinforcement is due to some lack of cognitive as well as evaluative resources. To be more specific, the response to the reward 
technique is explained by pointing out that consumers have not assimilated good enough knowledge and evaluations, such as ecological conscience (Bohlen et al., 1993); beliefs about recycling (Scholder, 1994); ecological concern (Dunlap and Van Liere; 1984; Bohlen et al., 1993); a favourable attitude toward recycling (Biswas et al., 2000) and recycling involvement (McGuiness et al., 1977; Black et al., 1985). Therefore, according to the classic framework, responders and non-responders are supposedly different given that non-responders are less involved than responders and have fewer resources in terms of ecological and recycling variables.

Nevertheless, the question is whether or not recycling continues to be of the high involvement category, and if it is not, whether to assume that responders and nonresponders to the reward technique display significant differences in terms of knowledge and evaluations. To understand this seemingly paradoxical framework it must be appreciated that nowadays recycling is often not a high involvement behaviour, since recycling has long since become part of contemporary culture and is no longer regarded as a novelty. Using on the innovation diffusion theory, we can assert that consumers are more likely to follow a low effort decision making process when the innovation is continuous and long-term (Rogers, 1995). In fact, consumers' learning requirements regarding recycling are easily satisfied since beliefs about recycling have already been acquired by the average citizen and the waste-collection system has reached a high standard of convenience which reduces its perceived cost (Ackerman, 1997). In short, Vining and Ebreo (1990) make it clear that the public's interpretation of environmental guidelines is routine, not necessarily ideological, and is very convenience-orientated.

Therefore, if we accept that recycling behaviour is now widespread throughout society, it would not seem logical to assume that there is a great difference between responders and non-responders in cognitive and evaluative terms. This in turn leads us to the conclusion that not only do non-responders and responders show similar degrees of recycling-related innovation, but also that, given the fact that they show the same level of resources, they should behave similarly under the reward conditions. According to several research works, when the recycling reward technique is applied, there are no significant changes in consumer cognitions and evaluations (Young, 1984; Katzev and Pardini, 1987; Vining and Ebreo, 1989). Consequently, both kinds of response must lead to similar levels of ecological and recycling resources in the consumer's mind. To test out these propositions, we put forward hypotheses 1 and 2 :

H1. Responders and non-responders to the recycling reward technique display no significant differences in their levels of ecological conscience, beliefs about recycling, ecological concern, attitude toward recycling and involvement with recycling prior to the promotion application.

H2. Responders and non-responders to the recycling reward technique show no significant differences in their levels of ecological conscience, beliefs about recycling, ecological concern, attitude toward recycling and involvement with recycling after the promotion application.

Many environmental studies have been content with limiting their studies to what occurs when consumers process information with a classic hierarchy of effect (knowfeel-do), and they have not ascertained empirically the degree to which consumers are involved in their recycling performance. This has led to the assumption that recycling behaviour is almost always high involvement, as explained by both the multiple
Different kinds of consumer response 
APJML

18,1

46 attribute theory and the reasoned action theory (Kok and Siero, 1985; Goldenhar and Connell, 1993; Taylor and Todd, 1995; Kalafatis et al., 1999).

Nevertheless, according to recent research, the high involvement decisions model is not the only one which is valid for explaining both ecological (Hartmann et al., 2002) and recycling behaviours (Ratneshwar et al., 2003) and it therefore seems possible to represent recycling behaviours by using other hierarchies of effect (Diaz and Beerli, 2004). Such approaches are based on the fact that (1) much previous evidence points to the existence of associations or correlations, and not of cause and effect relationships, in recycling adoption models (Schlegelmilch et al., 1996) and (2) no works have been found that contradict the protocol of classic effects.

In addition, the response to the reward technique is explained by the concept of low involvement. According to Petty and Cacioppo's elaboration likelihood model, the individual is not motivated to think about recycling but about the promised reward. Therefore, responders engage in recycling via the so called peripheral route and thus show little interest in recycling itself (Young, 1984; Katzev and Pardini, 1987; Vining and Ebreo, 1989).

Furthermore, supposing that recycling behaviour is in the final stage of the diffusion of the adoption process, the best hierarchy of effects to represent this desired conduct is the low involvement one whose sequence is described as "knowdo-feel" (Díaz and Beerli, 2005). This final stage is characterized by a high level of acceptance in terms of cognitions, evaluations and behaviours and implies that the rejection of the innovation has been reduced (Ram and Seth, 1989). Therefore, it would seem logical to assume that there are few opportunities to find differences between the responders' and non-responders' models of response to the reward technique and if any such differences do exist they would involve minor details. On the one hand, it is not difficult for the potential consumer to envisage the recycling behaviour and therefore non-response should not be seen as a reaction to the unknown. On the other hand, any resistance should not be conceived as the opposite of adoption, but as a normal consumer process, simply because the consumer's level of interest in recycling and the degree of concern about nature and the degree of inclination to recycle are obvious in society.

In this context, a definition of recycling resistance would have to be justified by the potential change from an existing status quo or because recycling conflicts with the dominant beliefs structure. But, respectively, require changes in existing habits and practices, generally offer little relative advantage to motivate change (Ram and Seth, 1989) and recycling is clearly consistent with the dominant philosophy of saving resources (Ackerman, 1997). Based on the above, the third hypothesis is proposed:

H3. The responders and non-responders models to the recycling reward technique do not show significant differences in their levels of structural relationships between ecological conscience, beliefs about recycling, ecological concern, attitude toward recycling and involvement with recycling.

Nobody can deny that the prize technique also maintains a certain level of the desired behaviour (Luyben and Bailey, 1979; Hamad et al., 1980), although to a lesser extent than other recycling promotion techniques. However, sustainers and non-sustainers should not display any significant differences since such recycling is in line with the dominant beliefs structure and, objectively, it may appear equally beneficial to most consumers' attitudes, such as ecological concern, attitude toward recycling and commitment with recycling. We previously mentioned that recycling has become a 
permanent part of our culture; in fact, primary education now covers basic environmental knowledge and therefore works to spread ecological conscience equally throughout the whole social system.

Moreover, as neither sustainers nor non-sustainers are reluctant to recycle and perceptions about a waste recovery programme are determined by dominant beliefs and attitudes, most consumers normally conclude that recycling is more convenient than inconvenient (Thogersen, 1994a,b; Schuhwerk and Leffkokk-Hagius, 1995; Shrum and Lowrey, 1995) and so the possibility of differences between sustainers and nonsustainers is limited to beliefs about recycling. In effect, collective waste programmes, in which consumers are the main providers of trash for recycling, are reaching a high standard of convenience and recycling is becoming a habit that is highly compatible with their existing lifestyle (Vining and Ebreo, 1990; Folz, 1991; Derksen and Gartrell, 1993).

In this context, sustainers and non-sustainers do not display significant differences since both kinds of response stem from the same opinion of recycling. In brief, most people are favourable to recycling in an advanced stage of the recycling adoption process. Based on this framework, we put forward the following hypothesis:

H4. Sustainers and non-sustainers to the recycling reward technique display no significant differences in their levels of ecological conscience, beliefs about recycling, ecological concern, attitude toward recycling and involvement with recycling before the promotion application.

The most widely accepted theoretical justification in the field of recycling to explain the success of programs based on prizes or positive reinforcement to sustain recycling behaviour is that proposed by the doctrine of instrumental learning (Wesley et al., 1995). According to this school of thought, prizes are non-conditional stimuli which, after being associated with the appearance of the desired response, result in reinforcing it up to the point that, in the absence of those stimuli, a recycling behaviour becomes more probable. As a consequence, the systematic guidelines of providing positive contingencies will make that behaviour more frequent by stimulating and consolidating it in an exogenous way (Wesley et al., 1995). Behaviourist psychology literature stresses that the reinforcement of a desired behaviour is achieved through prizes or gifts (Favell, 1977; Kazdin, 1980).

As mentioned above, the effect explained by this type of theoretical model basically consists of the reward techniques affecting behaviour directly and dispositions indirectly and after a period of time. In this respect, the theory of cognitive dissonance (Festinger and Carlsmith, 1957) not only justifies a process of adoption other than that of the reward technique, but also explains the change in beliefs and attitudes in line with the indirect effects of the previous appearance of the behaviour. According to the cognitive dissonance theory, individuals seek to maximize the internal psychological consistency of their cognitions, evaluations and behaviours, so that if inconsistency appears they will tend to alleviate that uncomfortable state of inconsistency.

Nevertheless, in applying this idea to the current recycling context, we propose that, when the reward technique provokes an immediate response in the public, those individuals do not display a dissonance relationship between their behaviours and their cognitions or evaluations since they already have a positive image of recycling. Therefore the increase in recycling conduct due to the reward promotion is something quite unrelated to any internal state of tension and thus any changes in the desired conduct are not accompanied by great internal readjustment. In other words, there is
Different kinds of consumer response 
APJML

18,1

48 limited cognitive dissonance to be reduced if ecological concern, ecological conscience, attitude toward recycling and involvement with recycling are already developed.

In addition, the lack of this cognitive dissonance effect is further supported if we consider that the reward technique emphasizes neither ecological content nor recycling itself. According to existing environmental literature, the application of the recycling reward technique does not consist of adding to the consumer's beliefs structure that recycling is something environmentally beneficial and to be ecologically concerned about. This reinforcement technique only consists of encouraging recycling behaviour by giving a gift to participants in a promotion program without any emphasis on ecological needs (McKenzie-Mohr, 1999).

Furthermore, if recycling is just a habit or a routine with a low involvement motivation, any change must be greatly reduced. Habit makes the consumer feel comfortable with the existing situation and where strength of habit towards the existing product is high, there is less motivation to change (Sheth, 1981). Thus, the normal distribution curve of the recycling adoption process is very advanced and the spread of a new incremental adoption is very limited. This would be true even if the reward technique was highly effective.

On the basis of the above, we put forward the final hypothesis:

H5: Sustainers and non-sustainers to the recycling reward technique display no significant differences in their levels of ecological conscience, beliefs about recycling, ecological concern, attitude toward recycling and involvement with recycling after the promotion application.

\section{Methodological aspects}

This research follows a quasi-experimental design. This type of treatment comprises the application of the reward technique by providing a draw-based prize. This reinforcement consisted of a free two-week stay for two people in a resort hotel. The technique was applied by 125 volunteers who each selected one member of their respective households as an experimental subject. Each volunteer was responsible for applying the treatment to that selected member. This procedure of using samples of convenience is recommendable when the collaboration of those surveyed requires, as in the case of this longitudinal research, intensive questionnaire completion. Furthermore, if those surveyed belong to the same social network as the surveyor, there is greater opportunity for observation and control of the individuals in the experiment.

Table I shows the chronogram of the experiment, which lasted almost three months although the promotion period itself was little more than a week. Once the information had been gathered it was entered into the data base and refined, eliminating cases with internal incoherence, in which the object of the research had been discovered by the individual being monitored and in those where the individual had stopped participating in the longitudinal study. After eliminating two entries, the real sample comprised 123 individuals, all of whom had a chance of receiving the prize by means of a draw.

A questionnaire was designed to gather the information related to the dependent variables. The questionnaire was issued three times and it gathered information about people's ecological and recycling beliefs and attitudes, as well as about their recycling behaviour. The questionnaire included the scales used to measure ecological conscience (Bohlen et al., 1993) which is defined as information about ecological matters and the causes of ecological damage (Bigné, 1997), beliefs about recycling (Scholder, 1994), knowledge about the how, what and why of recycling (Bagozzi and 


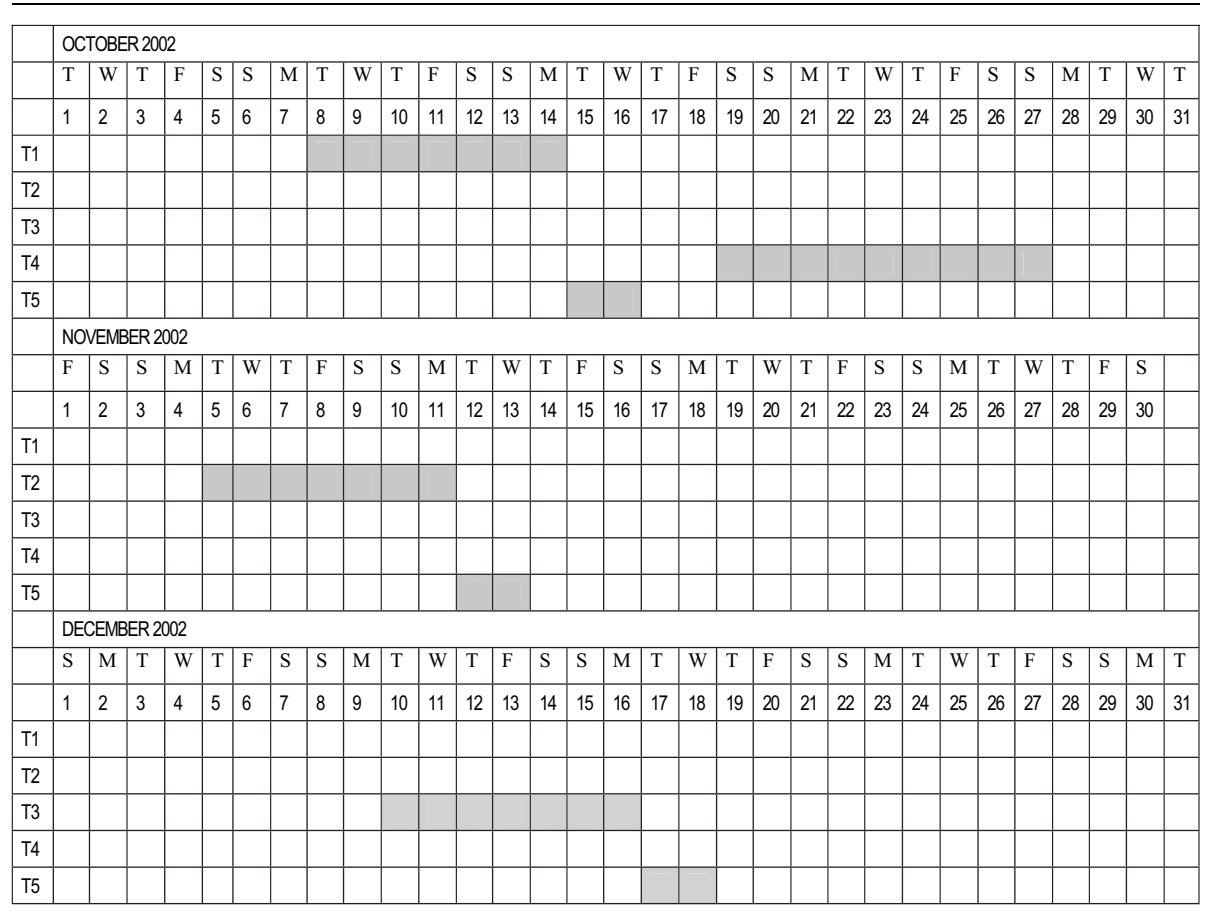

Notes: T1: Duration of the first issue of questionnaires and their return to the research director, T2: Duration of the second issue of questionnaires and their return to the research director, T3: Duration of the third issue of questionnaires and their return to the research director, T4: Duration of the promotions. T5: Data base processing.
Different kinds of consumer response

Table I. Program of activities

Dabholkar, 1994; Wesley et al., 1995) and ecological concern (Dunlap and Van Liere, 1984; Bohlen et al., 1993), which refers to feelings of disquiet about the deterioration of nature (Zimmer et al., 1994; Grunert and Jorn, 1995; Grendstad, 1999). All of the scales were 5-point Likert type scales. The questionnaire also included the instruments for measuring attitude toward recycling (Biswas et al., 2000) as a favourable, or unfavourable, inclination toward recycling (Oskamp et al., 1991; Shrum et al., 1994) and recycling involvement (McGuiness et al., 1977; Black et al., 1985; Zaichkowsky, 1985), which refers to a determined degree of concern or interest in recycling (Peattie, 1990; Simmons and Widmar, 1990; Oskamp et al., 1991; Alwitt and Pitt, 1996; Díaz and Beerli, 2002). Both of the instruments were semantic differentials. Although all the information related to recycling behaviour was gathered via the survey, we were able to control whether there were significant differences between the indirect measurement associated to the questionnaires and the direct measurements made by our contacted volunteers. 
APJML

18,1

50

\section{Analysis of results \\ Preliminaries}

Prior to testing the hypotheses, we checked the validity and reliability of the measuring instruments by means of exploratory factorial, Cronbach's alpha and confirmatory factorial analyses on the cognitive components and the evaluative, ecological and recycling components. Consequently, it can be said that the scales for ecological conscience, recycling beliefs, recycling attitude and involvement show values that indicate the reliability and validity of the dimensions under consideration, except for the extracted variance of ecological concern, which was below the critical threshold of 0.5. Finally, and in order to check the discriminatory validity of the measuring instruments, a correlations analysis was conducted which demonstrated that ecological conscience, recycling beliefs, ecological concern, recycling attitude and recycling involvement measure different ecological and recycling realities, with Pearson's correlation coefficient far below one.

\section{Testing hypothesis 1}

The first comment on the results obtained should highlight the evidence that the variables defined as ecological concern and conscience, are mid-scale score, much lower than the maximum of five. This contradicts the predominant understanding about recycling in environmental literature since recycling is not motivated by a very high commitment with a robust ecological ideology. Thus, as mentioned in the literature review, recycling appears be a solid part of our contemporary culture, i.e. a routine without any radical connotations (Vining and Ebreo, 1990).

Furthermore, another aspect of the classic framework challenged by the results stems from a means differences test to compare the responders and non-responders to the reward technique. On the one hand, as Table II shows, responders and nonresponders diverge only at the level of ecological conscience since responders are more aware of environmental matters than non-responders. This conflicts with the predominant evidence obtained in previous work that a lower level of environmental education as motivation for the desired conduct in a consumer represents a straightforward route to success in the reward recycling technique. These results might suggest the idea that recycling is in an advanced phase of the adoption process and thus non-response must be understood as acquiescence to recycling rather than mere opposition or reluctance.

This heterodox explanation receives additional support since there are no statistically significant differences between responders and non-responders in their levels of beliefs about recycling, ecological concern, attitude toward recycling and involvement with recycling. Thus, responders and non-responders alike may accept the

Table II.

Means difference test (MDT) and student $t$ test of related samples (STTRS) to examine the immediate response to the reward recycling technique

\begin{tabular}{|c|c|c|c|c|c|c|c|}
\hline Phase & Intra-groups & $\mathrm{N}$ & Conscience & Beliefs & Concern & Attitude & Involvement \\
\hline \multirow[t]{3}{*}{$\mathrm{T} 1$} & Non increasing & 74 & 2,9438 & 2,3509 & 2,4959 & 3,0540 & 3,1636 \\
\hline & Increasing & 49 & 3,1658 & 2,4431 & 2,5382 & 2,9769 & 3,2050 \\
\hline & Significance MDT & & 0.054 & 0.337 & 0.565 & 0.695 & 0.782 \\
\hline \multirow[t]{3}{*}{$\mathrm{T} 2$} & Non increasing & 74 & 2,7696 & 2,5656 & 2,1472 & 3,0149 & 3,1094 \\
\hline & Increasing & 49 & 2,7407 & 2,7245 & 2,2540 & 3,3282 & 3,3284 \\
\hline & Significance MDT & & 0.737 & 0.068 & 0.147 & 0.058 & 0.120 \\
\hline \multirow[t]{2}{*}{$\mathrm{T} 1-\mathrm{T} 2$} & Sig. Non inc. (STTRS) & & 0.005 & 0.000 & 0.000 & 0.653 & 0.433 \\
\hline & Sig. Increas. (STTRS) & & 0.000 & 0.001 & 0.000 & 0.012 & 0.211 \\
\hline
\end{tabular}


idea of recycling, but the latter are unwilling or unable to increase their collaboration for other reasons. In terms of the innovation diffusion theory, Gatignon and Robertson (1989) would say that non-increase of the desired conduct must be explained as postponement rather than rejection.

On this basis, we can conclude that hypothesis 1 is verified, since responders and non-responders to the recycling reward technique display no significant differences in their levels of beliefs about recycling, ecological concern and involvement with recycling although attitude toward recycling before the promotion application.

\section{Testing hypothesis 2}

For the longitudinal analysis, a Student t-test of related samples was used to identify the intensity and direction of the changes in both ecological and recycling components. In addition, a means difference test was performed with the aim of examining whether there is any discrepancy in any of mentioned components after the withdrawal of the promotion ( $t 2$ ). As shown in Table II, the prize technique has positive and statistically significant effects on beliefs about recycling immediately after the promotion is applied. Hence, responders and non-responders both increase their knowledge about what, how and why to recycle with the same significance, even if responders change a little more than non-responders due to the increase in their conduct. On the other hand, the ecological components reduce their presence after the promotional technique is applied. This negative evolution is not contrary to our expectations and it could be due to the fact that this promotion to encourage recycling does not emphasize any environmental content, which may be disassociating the idea of recycling from any ecological content in the target mind. In fact, according to Vining and Ebreo (1990), the public's interpretation of environmental guidelines is not necessarily ecological.

In contrast, the attitude toward recycling shows a statistically significant difference depending on whether or not consumers have increased their collaboration with recycling. To be more specific, while responders display an increasingly favorable attitude toward recycling, non-responders do not display any change in terms of their evaluation of recycling. In fact, after the promotion has been applied, the former show a higher degree of favourability toward recycling than the latter. This is in line with the theory of consistency between attitudes and behaviour and moreover, a certain effect of reward may directly favour that consistency. Nevertheless, involvement with recycling remains permanent given that there is no relevant change either from a longitudinal perspective or from a comparative approach between responders and non-responders. This adds to the evidence that recycling is no longer a desired conduct with high involvement and might become a stable habit just for the sake of following a steady routine. Thus, even though there are some differences with respect to attitude toward recycling, hypothesis 2 , which states that responders and non-responders to the recycling reward technique show no significant differences in their the evolution of ecological conscience, beliefs about recycling, ecological concern recycling and involvement with recycling after the promotion application, can be considered verified.

\section{Testing hypothesis 3}

To test hypothesis 3 , a structural or transversal analysis was conducted using a path model analysis. To be more specific, several alternative path models were estimated, keeping the low involvement hierarchy of effects format with the aim of selecting the one whose specification best represents the immediate response to the reward recycling technique. Subsequently, and following Gerbing and Andersen (1988) and Hair et al.
Different kinds of consumer response 
APJML 18,1

\section{2}

Figure 1.

Chi square means differences test within a multi-groups analysis: to represent those who respond and do not respond to the reward recycling technique at $\mathrm{t} 2$ (low involvement)

(1999), the goodness of fit indicators of the estimated models were compared in order to choose a final model. In the study of immediate response to the reward recycling promotion, the sub-sample selected in $\mathrm{t} 2$ comprised those responding to the prize technique. Additionally, we estimated the best models within the classic hierarchy of effects and compared their goodness of fit indicators to demonstrate that this selected model displays worse fits than the low-involvement model.

As Figure 1 shows, the selected model shows a good fit to the data in all the indicators for the sub-sample formed by those who responded to the reward technique at t2. This model corresponds to the hierarchy of effects which is known as "learn-dofeel" in Kotler and Roberto's terminology (1992), and which establishes the sequence of behaviour adoption characterized by low involvement. After this model was selected, we performed the same model for the non-responders sample in order to demonstrate that the responders model can also represent the non-increasing adoption process after the promotion has been applied.

Finally, we performed a multi-group analysis taking into account the trait of responders and non-responders to the reward recycling technique. Chi squared differences tests were applied between the model without restrictions and each of the models with an established restriction of equality of parameters of regression in the groups with an increase of collaboration and without this increase (see Table III). The results show that there are no significant differences in the level of response to the reward recycling technique, with a reliability of 95 per cent.

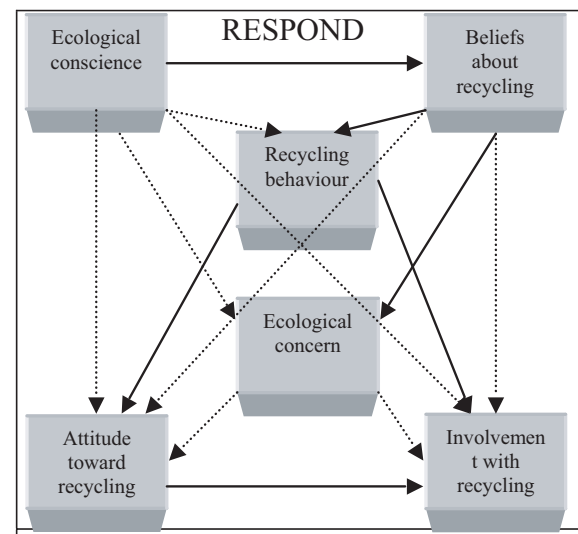

CRITICAL RATIOS AND STANDARDIZED ESTIMATORS Ecological conscience $\rightarrow$ Beliefs about recycling (EE: $0.55 ; \mathrm{RC}: 7.14)$ Ecological conscience $\rightarrow$ Recycling behaviour (EE: $0.06 ;$ RC: 0.60 )

Ecological conscience $\rightarrow$ Ecological concern (EE: $0.11 ;$ RC: 0.74$)$

Ecological conscience $\rightarrow$ Attitude toward recycling (EE: $0.06 ;$ RC: 0.66 )

Ecological conscience $\rightarrow$ Involvement with recycling (EE: 0.06 ; RC: 0.51 )

Beliefs about recycling $\rightarrow$ Recycling behaviour (EE: $0.35 ;$ RC: 3.43 )

Beliefs about recycling $\rightarrow$ Attitude toward recycling (EE: $0.05 ; \mathrm{RC}: 0.57)$

Beliefs about recycling $\rightarrow$ Involvement with recycling (EE: 0.09; RC: 1.05 )

Beliefs about recycling $\rightarrow$ Ecological concern (EE: $0.39 ;$ RC: 2.55 )

Recycling behaviour $\rightarrow$ Attitude toward recycling (EE: $0.65 ;$ RC: 8.77 ) Recycling behaviour $\rightarrow$ Involvement with recycling (EE: $0.26 ; \mathrm{RC}: 2.88)$

Ecological concern $\rightarrow$ Attitude toward recycling (EE: $-0.05 ;$ RC: -0.66$)$

Ecological concern $\rightarrow$ Involvement with recycling (EE: $0.02 ; \mathrm{RC}: 0.27$ )

Attitude toward recycling $\rightarrow$ Involvement with recycling (EE: 0.37 ; RC: 4.23 )



CRITICAL RATIOS AND STANDARDIZED ESTIMATORS Ecological conscience $\rightarrow$ Beliefs about recycling (EE: $0.54 ;$ RC: 7.14 ) Ecological conscience $\rightarrow$ Recycling behaviour (EE: $0.05 ;$ RC: 0.60 ) Ecological conscience $\rightarrow$ Ecological concern (EE: $0.05 ; \mathrm{RC}: 4.55$ ) Ecological conscience $\rightarrow$ Attitude toward recycling (EE: $0.06 ;$ RC: 0.66 ) Ecological conscience $\rightarrow$ Involvement with recycling (EE: $0.20 ;$ RC: 2.10 )

Beliefs about recycling $\rightarrow$ Recycling behaviour (EE: 0.33 ; RC: 3.43 ) Beliefs about recycling $\rightarrow$ Attitude toward recycling (EE: $0.04 ; \mathrm{RC}: 0.57$ ) Beliefs about recycling $\rightarrow$ Involvement with recycling (EE: $0.08 ; \mathrm{RC}: 1.05$ )

Beliefs about recycling $\rightarrow$ Ecological concern (EE: -0.15; RC: - 1.26 ) Recycling behaviour $\rightarrow$ Attitude toward recycling (EE: $0.0 .63 ; \mathrm{RC}: 8.77$ ) Recycling behaviour $\rightarrow$ Involvement with recycling (EE: 0.26 ; RC: 2.88 ) Ecological concern $\rightarrow$ Attitude toward recycling (EE: -0.04 ; RC: -0.66 ) Ecological concern $\rightarrow$ Involvement with recycling (EE: $0.02 ; \mathrm{RC}: 0.27$ ) Attitude toward recycling $\rightarrow$ Involvement with recycling (EE: $0.37 ; \mathrm{RC}: 4.23$ ) 
Equity restrictions for weight regression for sub-samples relative to non responds vs responds.

Ecological conscience $\rightarrow$ Beliefs about recycling

Ecological conscience $\rightarrow$ Recycling behaviour

Ecological conscience $\rightarrow$ Ecological concern

Ecological conscience $\rightarrow$ Attitude toward recycling

Ecological conscience $\rightarrow$ Involvement with recycling

Beliefs about recycling $\rightarrow$ Recycling behaviour

Beliefs about recycling $\rightarrow$ Attitude toward recycling

Beliefs about recycling $\rightarrow$ Involvement with recycling

Beliefs about recycling $\rightarrow$ Ecological concern

Recycling behaviour $\rightarrow$ Attitude toward recycling

Recycling behaviour $\rightarrow$ Involvement with recycling

Ecological concern $\rightarrow$ Attitude toward recycling

Ecological concern $\rightarrow$ Involvement with recycling

Attitude toward recycling $\rightarrow$ Involvement with recycling

- Equity in all regression weight

- equity in all regression weight, except in significant parameters

REWARD

CMIN

0.08

0.95

5.95

1.24

3.16

0.12

1.44

1.66

7.36

1.07

0.48

0.00

0.30

1.81

18.57

8.59

\begin{tabular}{rc} 
DF & $p$ \\
\hline 1 & 0.87 \\
1 & 0.62 \\
1 & 0.01 \\
1 & 0.53 \\
1 & 0.08 \\
1 & 0.86 \\
1 & 0.48 \\
1 & 0.41 \\
1 & 0.00 \\
1 & 0.58 \\
1 & 0.76 \\
1 & 0.95 \\
1 & 0.81 \\
1 & 0.36 \\
14 & 0.12 \\
11 & 0.77
\end{tabular}

Different kinds of consumer response

Table III.

Chi square means differences test

However, if we analyse the differences in the regression coefficients of each of the relationships specified in the model, it can be seen that there are statistically significant differences at a relationship parameter level.

An examination of the critical ratios and standardized estimators of the multi-group analysis allows us to draw conclusions about the type of relationships according to the level of response. To be specific, there are two minor differences. The first is that ecological conscience influences both involvement with recycling and ecological concern in the case of the non-responders but not in the case of responders. However, in spite of these differences, the increasing adoption of the desired conduct due to the reward promotional technique is not a direct consequence of some degree of ecological conscience since knowledge about how and why to recycle is the immediate cognitive antecedent of consumers increasing their recycling behaviour. Consequently, although ecological conscience plays a more important role in the case of non-responders, that knowledge about environmental issues is not relevant to recycling conduct but is relevant to the degree of involvement with recycling and the feeling of ecological concern in the case of non-responders.

Secondly, beliefs about recycling are a cause of ecological concern in responders but this relationship is not significant in the case of non-responders. Again this result does not imply that the increased conduct provoked by the recycling reward technique causally diverges from the non-increased conduct since ecological concern is not linked to any further variable within the recycling adoption process. In fact, although this difference exists between responders and non-responders, it only means that responders to the reward technique show a higher degree of ecological concern based on certain knowledge about how and why to recycle. In other words, their concern about the deterioration of nature is not useful to recycling even if it does represent a more practical basis.

Thus, considering that the Chi Square Differences Test shows there are no significant differences in the levels of response to the reward recycling technique, and that the mentioned differences at some relationship parameter levels are not relevant to an increase the desired conduct, hypothesis 3 is verified. Therefore, responders and 
APJML 18,1

54

Table IV.

Means difference test (MDT) and student $t$ test of related samples (STTRS) to exam the immediate and sustained response to the reward recycling technique non-responders models to the recycling reward technique display no significant differences in their levels of structural relationship among ecological conscience, beliefs about recycling, ecological concern, attitude toward recycling and involvement with recycling.

\section{Testing hypothesis 4}

In order to ascertain whether there exist are significant differences between sustainers and non-sustainers in terms of cognitions and evaluations, we conducted a means differences test. As Table IV shows, sustainers were more ecologically concerned than non-sustainers before the promotion was applied. Therefore, a feeling of disquiet is the only aspect to distinguish sustainers from non-sustainers, highlighting the fact that this concern about the deterioration of nature favours the success of the reward recycling technique. According to psychological literature, this evidence might be explained by the fact that a low level of fear often works as an incentive to activate the memory process in consumers' minds (Eysenck, 1992) and could thus prompt the desired recycling conduct to appear.

However, there are no further differences since sustainers and non-sustainers show the same levels of ecological conscience, beliefs about recycling, attitude toward recycling and involvement with recycling, before, immediately after, and one month after the application of the promotion. Therefore, it is clear that, although sustainers show a higher level of disquiet about the deterioration of nature than non-sustainers before the promotion application, hypothesis 4 is verified.

\section{Testing hypothesis 5}

As shown in Table IV, a student t-test for related samples indicates that a sustained response to the prize promotion technique involves significant changes both in cognitive and in evaluative components among those who respond to the prize technique just after the promotion is applied and who maintain their response one month later. To be more specific, ecological conscience, beliefs about recycling and attitude toward recycling present show a significant increase in the case of sustainers. On the other hand, non-sustainers do not show any changes except in beliefs about recycling. The reward promotion mechanism works because consumers like a

\begin{tabular}{|c|c|c|c|c|c|c|c|}
\hline Time & & $N$ & Conscience & Beliefs & Concern & Attitude & Involvement \\
\hline \multirow[t]{2}{*}{$\mathrm{T} 1$} & Non-sustainers & 21 & 3,2315 & 2,4375 & 2,4006 & 3,2239 & 3,2292 \\
\hline & Sustainers & 28 & 3,1166 & 2,4473 & 2,6413 & 2,7917 & 3,1869 \\
\hline \multicolumn{2}{|c|}{ Signific. (MDT) } & & 0.487 & 0.945 & 0.05 & 0.153 & 0.853 \\
\hline \multirow[t]{3}{*}{$\mathrm{T} 2$} & Non-sustainers & 21 & 2,7323 & 2,6882 & 2,2113 & 3,3391 & 3,3092 \\
\hline & Sustainers & 28 & 2,7470 & 2,7518 & 2,2861 & 3,3201 & 3,3427 \\
\hline & ific. (MDT) & & 0.91 & 0.63 & 0.49 & 0.93 & 0.86 \\
\hline \multirow[t]{3}{*}{ T3 } & Non-sustainers & 21 & 3,2381 & 2,8437 & 2,6516 & 3,4167 & 3,3391 \\
\hline & Sustainers & 28 & 3,3105 & 2,9722 & 2,7128 & 3,4956 & 3,4610 \\
\hline & Signific. (MDT) & & 0.61 & 0.36 & 0.68 & 0.69 & 0.51 \\
\hline T1-T2 & (STTRS) & & 0.000 & 0.101 & 0.137 & 0.597 & 0.619 \\
\hline \multicolumn{3}{|c|}{ Sig. Sustainer (STTRS) } & 0.000 & 0.001 & 0.000 & 0.004 & 0.220 \\
\hline $\mathrm{T} 2-\mathrm{T} 3$ & \multicolumn{2}{|l|}{$\begin{array}{l}\text { Sig. Non sust. } \\
\text { (STTRS) }\end{array}$} & 0.000 & 0.190 & 0.002 & 0.473 & 0.822 \\
\hline \multicolumn{3}{|c|}{ Sig. Sustainer(STTRS) } & 0.000 & 0.022 & 0.000 & 0.121 & 0.277 \\
\hline
\end{tabular}


stimulus and it creates positive feelings or emotions and this positive attitude toward a stimulus can be extended to recycling and make attitudes toward recycling more positive. In this case, the meaning of the brand, rather than the brand itself, is new and attractive, which explains why this brand can persistently meet the consumer's hedonistic needs (Edell and Staelin, 1983).

However, this theory does not contradict the fact that the changes must be similar in the evolution of the two kinds of response: sustainers and non-sustainers. In fact, according to the means difference test result, hypothesis 5 can be accepted since sustainers and non-sustainers to the recycling reward technique display no significant differences in their levels of ecological conscience, beliefs about recycling, ecological concern, attitude toward recycling and involvement with recycling after the promotion application.

In the case of involvement with recycling not only is there no significant change in any phase of its development, but there is no difference between the sustainers and non-sustainers when the promotion is withdrawn. This evidence implies that sustained and non-sustained responses are very similar processes of adoption and that they should therefore not be regarded as opposites. Thus, resistance in this phase of the recycling adoption process is effectively conceived as a normal consumer process, since most people are fairly acquiescent with respect to recycling. According to Gatignon and Robertson (1989), reluctance to sustain the desired response might be due to a simple postponement phenomenon rather than outright rejection. Postponers or nonsustainers not wishing to sustain at a particular time adopt such a posture because they want more information or more facilities, while rejectors have processed the information or been provided the facilities they need to make the decision not to sustain. Therefore, non-sustainers are individuals who have accepted recycling but postpone maintenance until an appropriate time or situation arises.

\section{Conclusions}

The general idea that recycling is explained by the classic belief-based model of attitude is highly plausible and, consequently, it seems obvious that one natural avenue to encourage recycling behaviour involves influencing cognitions. This classic paradigm to conceive environmental behaviour proposes that people need to process a large amount of information about ecology in order to perform the recycling conduct and it assumes that recycling is a high involvement desired conduct. Hence, it is not surprising that the classic belief-based model of recycling adoption has received such attention from practitioners and from scholars in the environmental literature.

Nevertheless, this predominant environmental paradigm framed within a high involvement theory was developed some decades ago, when enthusiasm for recycling probably entailed devoting great effort to volunteer waste collection. In contrast, this research work offers some challenging empirical evidence challenging four old presumptions concerning the understanding of recycling. They demonstrate that long gone are the days when:

(1) recycling behaviour was carried out with a very high involvement conduct requiring great cognitive processing effort;

(2) the responders to the reward recycling technique showed a low intrinsic interest in recycling

(3) the response and the non-response displayed significant differences in terms of beliefs and attitudes and
Different kinds of consumer response

55 
APJML

18,1
(4) the difference between the maintenance and non-maintenance of the desired conduct after the promotion application was due to some changes in developing cognitions and evaluations of ecology in the case of maintenance.

On the basis of the above, fresh facts and new ideas to update the recycling classic theoretical framework are put forward. The main idea relates to evidence that desired behaviour has become a routine or habit with recognized awareness of ecology and recycling, but without a high level of involvement since today's adoption process does not require such effort. This implies that the efficacy of the reward technique has been transformed and consequently its effects must be understood differently. To be more specific, today's responders should be identified further since: (1) responders and nonresponders are similar, both before and after the promotion has been applied, in terms of their levels of beliefs about recycling, ecological concern and involvement with recycling and (2) both show the same model of adoption with a low hierarchy of effect and with a few minor differences. In addition, a more detailed examination of present sustainers is required given that there is only one difference between sustainers and non-sustainers, namely, the sustainers' greater ecological concern before the promotion application. Consequently, non-response to the reward technique becomes less threatening to recycling since it is conceived, as Ram (1987) suggested, neither as the opposite of the desired adoption, nor as being different to it: on the contrary, it is actually very similar since nonresponse is conceived in the same way as the normal consumer adoption process.

Some practical implications that might stem from these results involve an understanding that recycling takes place in an advanced stage of the diffusion process. According to the literature on diffusion of innovations about consumer learning requirements, it would seem logical to consider that, at this phase, most people do not resist recycling since they believe in the necessity for it and in its value. Moreover, they have experience of adoption, consider it easy to perform and support its diffusion. Therefore, at this stage the empirical evidence indicates that, the point of resistance refers to a lack of ecological conscience since responders to the reward technique show a higher degree of knowledge about environmental problems and how to manage them. Furthermore, as the attitude toward recycling is transformed significantly in the case of responders, it would seem desirable to suggest a marketing effort to guarantee a favourable opinion of recycling by means an attractive reward or prize. Both recommendations are relevant not only to increasing recycling behaviour but also to sustaining the desired conduct in the long term. In fact, the most significant differences between sustainers and non-sustainers are found in the levels and evolution of ecological conscience and attitudes to recycling. Moreover, ecological concern is higher in the case of sustainers, which means that a certain degree of disquiet about environmental deterioration may be useful in terms of increasing the permanent effectiveness of the recycling reward technique. Therefore, the organisation of a lottery should be accompanied by some communication about environmental damage with the aim of raising ecological concern.

Although resistance to recycling is not a real rejection or reluctance, it is predictable that the next stage will give rise to this kind of problem. Hence, future lines of research should provide more insight into reluctance to recycle because increased recycling will depend on overcoming unfavourable opinion, conflicting values and finding a divergent route to achieve the collaboration of society as a whole in recycling. In this respect, more effort must be devoted to the psychographic characteristics of reluctance since, once innovation is widely diffused, resistance comes from this kind of variable 
(Sheth, 1981; Martínez et al., 1998). We refer to the reactance principle (Brehm, 1966; Snyder and Fronkin, 1980), the sense of group anti-conformation (Strickland et al., 1970) and the materialistic trend of considering personal beliefs and attitudes as possessions (Abelson and Prentice, 1989).

\section{Different kinds of consumer response}

\section{References}

Abelson, R. and Prentice, D. (1989), "Beliefs as possessions: a functional perspective", in Pratkanis, A.R., Breckler, S.J., and Greenwald, A.G. (Eds), Attitude Structure and Function, Erlbaum, Hilldale, NJ: pp. 361-81.

Ackerman, F. (1997), Why do We Recycle?, Island Press, Covelo, CA.

Alwitt, L. and Pitts, R. (1996), "Predicting purchase intentions for an environmentally sensitive product”, Journal of Consumer Psychology, Vol. 5 No. 1, pp. 49-64.

Bagozzi, R. and Dabholkar, P. (1994), "Consumer recycling goals and their effect on decisions to recycle: a mean end chain analysis", Psychology and Marketing, Vol. 11, pp. 1-28.

Bigné, E. (1997), "El consumidor verde: bases de un modelo de comportamiento", Esic-Market, Vol. 50, pp. 237-51.

Biswas, A., Licata, J., Mckee, D., Pullig, C. and Daughtridge, C. (2000), "The recycling cycle: an empirical examination of consumer waste recycling and recycling shopping behaviors", Journal of Public Policy and Marketing, Vol. 19, pp. 93-105.

Black, J., Stern, P. and Elworth, J. (1985), "Personal and contextual influences on household energy adaptations", Journal of Applied Psychology, Vol. 70, pp. 3-21.

Bohlen, G., Schlegelmilch, B. and Diamantopoulos, A. (1993), "Measuring ecological concern: a multi-construct perspective”, Journal of Marketing Management, Vol. 9, pp. 415-30.

Brehm, J. (1966), A Theory of Psychological Reactance, Academic Press, New York, NY.

Cacioppo, J. and Petty, R. (1984), "The elaboration likelihood model of persuasion", Advances in Consumer Research, Vol. 11, pp. 673-75.

Dahle, M. and Neumayer, E. (2001), "Overcaming barriers to campus greening: a survey among higher educational institutions in London, UK", International Journal of Sustainability in Higher Education, Vol. 2 No. 2, pp. 139-59.

Derksen, L. and Gartrell, J. (1993), “The social context of recycling”, American Sociological Review, Vol. 58, pp. 434-42.

Diaz, G. and Beerli, A. (2002), "Cómo son las personas resistentes a reciclar: una aplicación empírica al reciclaje de vidrio", Best Papers Proceedings (2002), XVI Congreso Nacional y XII Congreso Hispano Francés, Alicante.

Díaz, G. and Beerli, A. (2005), "La no respuesta a la promoción del reciclado mediante la técnica del blockleader y el compromiso", XVII Encuentro de profesores universitarios de marketing, Madrid.

Diaz, G., Beerli, A. and Martin, J. (2004), "El modelo de hábito de reciclado según el perfil sociodemográfico de los consumidores", XVI Encuentro de Profesores Universitarios de Marketing, Alicante.

Dunlap, R. and Van Liere, D. (1984), "Commitment to the dominant social paradigm and concern for environmental quality”, Social Science Quarterly, Vol. 65 No. 4, pp. 1013-28.

Eysenck, M. (1992), Anxiety: The Cognitive Perspective, Lawrence Erlbaum Associates, Hove.

Favell, E. (1977), The Power of Positive Reinforcement: A Handbook of Behavior Modification, Charles C. Thomas. California, Springfield, IL.

Festinger, L. and Carlsmith. (1957), A Theory of Cognitive Dissonance, Stanford University Press, Stanford, CT. 
APJML 18,1

Folz, D. (1991), "Recycling program design, management and participation: a national survey of municipal experience", Public Administration Review, Vol. 51 No. 3, pp. 222-31.

Gatignon, H. and Robertson, T. (1989), "Technology diffusion: an empirical test of competitive effects”, Journal of Marketing, Vol. 53 No. 1, pp. 35-49.

Geller, E., Chafee, J. and Ingram, R. (1975), "Promoting paper recycling on a university campus", Journal of Environmental Systems, Vol. 5 No. 1, pp. 39-57.

Gerbing, D. and Anderson, J. (1988), "An updated paradigm for scale development incorporating unidimensionality and its assessment”, Journal of Marketing Research, Vol. 25, pp. 186-92.

Goldenhar, L. and Connell, C. (1993), "Understanding and predicting recycling behavior: an application of the theory of reasoned action”, Journal of Environmental Systems, Vol. 22 No. 1, pp. 91-103.

Grendstad, G. (1999), "The new ecological paradigm scale: examination and scale analysis", Environmental Politics, Vol. 8 No. 4, pp. 194-205.

Grunert, S. and Jorn, H. (1995), "Values, environmental attitudes, and buying of organic foods", Journal of Consumer Marketing, Vol. 16, pp. 39-62.

Hair, J., Anderson, E., Tatham, R. and Black, W. (1999), Análisis multivariante, 5th ed., Editorial Prentice Hall.

Hamad, D., Bettinger, R., Cooper, D. and Semb, G. (1980), "Using behavioral procedures to stablish an elementary school paper recycling program”, Journal of Environmental Systems, Vol. 10, pp. 149-56.

Hartmann, P., Forcada, F. and Apaolaza, V. (2002), "Atributos intangibles de marcas ecológicas: un estudio experimental del efecto diferenciado de los beneficios emocionales en la posición percibida de la marca”, Best Papers Proceedings del XVI Congreso Nacional y XII Congreso Hispano Francés, Alicante.

Hopper, J. and Nielsen, J. (1991), "Recycling as altruistic behavior. Normative and behavioral strategies to expand participation in a community recycling residence", Environment and Behavior, Vol. 23 No. 2, pp. 195-20.

Kalafatis, S., Pollard, M., East, R. and Tsogas, M. (1999), "Green marketing and Ajzen's theory of planned behavior: a cross market examination”, Journal of Consumer Marketing, Vol. 16 No. 5, pp. 441-60.

Katzev, R. and Pardini, A. (1987), "The comparative effectiveness of reward and commitment approaches in motivating community recycling", Journal of Environmental Systems, Vol. 17, pp. 93-113.

Kazdin, E. (1980), Behavior Modification in Applied Settings, Dorsey Press, Homewood, IL.

Kok, G. and Siero, S. (1985), "Tin recycling: awareness, comprehension, attitude, intention and behavior”, Journal of Economic Psychology, Vol. 16, pp. 157-73.

Kotler, P. and Roberto, E. (1992), Marketing social, Diez de Santos Editorial, Madrid.

Lansana, F. (1992), "Distinguishsing potential recyclers from non recyclers: a basis for developing recycling strategies”, The Journal of Environmental Education, Vol. 23, pp. 16-23.

Leeming, F., Dwyer, W., Porter, B. and Cobern, M. (1993), "Outcome research in environmental education: a critical review”, Journal of Environmental Education, Vol. 24, pp. 8-21.

Luyben, P. and Bailey, J. (1979), "Newspaper recycling: the effects of rewards and proximity of containers", Environment and Behavior, Vol. 11 No. 4, pp. 539-57.

McGuiness, J., Jones, P. and Cole, G. (1977), “Attitudinal correlates of recycling behavior”, Journal of Applied Psychology, Vol. 62, pp. 376-84.

McKenzie-Mohr, D. (1999), Fostering Sustainable Behavior, New Society Publisher, Philadelphia, PA. 
Martínez, E., Polo, Y. and Flavián, C. (1998), "The acceptance and diffusion of new consumer durables: differences between first and last adopters", Journal of Consumer Marketing, Vol. 15 No. 4, pp. 323-42.

Needleman, L. and Géller, E. (1992), "Comparing interventions to motivate work-site collection of home generated recyclables", American Journal of Community Psychology, Vol. 20, pp. $775-85$.

Oskamp, S., Harrington, M., Edwards, T., Sherwood, D., Okuda, S. and Swanson, D. (1991), "Factors influencing household recycling behavior", Environment and Behavior, Vol. 23 No. 4, pp. 494-519.

Peattie, K. (1990), "Panting marketing education or how to recycle old ideas", Journal of Marketing Management, Vol. 2, pp. 105-25.

Ram, S. (1987), "A model of innovation resistance" in M. Wallendorf and Anderson (Eds), Advances in Consumer Research, 14. Association for Consumer Research, Provo, UT.

Ram, S. and Sheth, J. (1989), "Consumer resistance to innovations: the marketing problem and its solutions", Journal of Consumer Marketing, Vol. 6 No. 2, pp. 5-14.

Ratneshwar, S., Glen, D. and Huffman, C. (2003), The Why of Consumption: Contemporary Perspectives on Consumer Motives, Goals and Desires, Routledge Taylor and Francis Group. London.

Rogers, E. (1995), The Diffusion of Innovations, 3rd ed., The Free Press, New York, NY.

Sheth, J. (1981), "Psychology of innovation resistance: the less developed concept (LDC) in diffusion research", Research in Marketing, Vol. 4, pp. 273-82.

Schlegelmilch, B., Bohlen, G. and Diamantopoulos. (1996), "The link between green purchasing decisions and measures of environmental consciousness", European Journal of Marketing, Vol. 30, No. 5, pp. 35-55.

Scholder, P. (1994), "Do we know what we need to know? Objective and subjective knowledge effects on pro-ecological behaviors”, Journal of Business Research, Vol. 30, pp. 43-52.

Schuhwerk, M. and Lefkokk-Hagius, R. (1995), "Green or non green? Does type of appeal matter when advertising a green product?”, Journal of Advertising, Vol. 24, pp. 45-55.

Shrum, L. and Lowrey, T. (1995), "Applying social and traditional marketing principles to the reduction of household waste”, American Behavioral Scientist, Vol. 38, No. 4, pp. 646-58.

Shrum, L., Lowrey, T. and Mc Carty, J. (1994), "Recycling as a marketing problem: a framework for strategy development”, Psychology and Marketing, Vol. 11, pp. 393-416.

Simmons, D. and Widmar, R. (1990), "Motivations and barriers to recycling: toward a strategy for public education", Journal of Environmental Education, Vol. 12, pp. 13-18.

Snyder, C. and Fromkin, H. (1980), Uniqueness: The Human Pursuit of Difference, Plenum Press, New York, NY.

Strickland, L., Messick, S. and Jackson, D. (1970), "Conformity, anticonformity and independence: their dimensionality and generality", Journal of Personality and Social Psychology, Vol. 16, pp. 497-507.

Taylor, S. and Todd, P. (1995), "Understanding household garbage reduction behavior: a test of an integrated model”, Journal of Public Policy and Marketing, Vol. 14 No. 2, pp. 192-204.

Thogersen, J. (1994a), "A model of recycling behavior, with evidence from danish source separation pregrammes", International Journal of Research in Marketing, Vol. 11, pp. $145-63$.

Thogersen, J. (1994b), "Monetary incentives and environmental concern. Effect of a differentiated garbage fee", Journal of Consumer Policy, Vol. 17, pp. 407-42.

Vining, J. and Ebreo, A. (1989), "An evaluation of the public response to a community recycling education program”, Society and Natural Resource, Vol. 2, pp. 23-36.
Different kinds of consumer response 
APJML 18,1

60
Vining, J. and Ebreo, A. (1990), "What's makes a recycler? A comparison of recyclers and non recyclers", Environmental and Behavior, Vol. 22 No. 1, pp. 55-73.

Wesley, P., Oskamp, S. and Mainieri, T. (1995), "Who recycles and when?. A review of personal and situational factors", Journal of Environmental Psychology, Vol. 15, pp. 105-21.

Witmer, J. and Geller, E. (1976), "Facilitating paper recycling effects of prompts, raffles and contest”, Journal of applied Behavior Analysis, Vol. 9, pp. 315-22.

Young, R. (1984), "Motivating people to recycle: the use of incentives", Resource Recycling, Vol. 42, pp. 14-15.

Zimmer, M., Stafford, T. and Royne, M. (1994), "Green issues: dimensions of environmental concern”, Journal of Business Research, Vol. 30, pp. 63-74.

Zaichkowsky, J. (1985), "Measuring the involvement construct”, Journal of Consumer Research, Vol. 12, pp. 341-52.

\section{About the authors}

Gonzalo Díaz Meneses specializes in consumer behaviour, particularly in the application of marketing to non-profit organizations, social marketing and public policy. He is the author of two books and has published more than fifty articles and conference papers. He is a $\mathrm{PhD}$ lecturer at the University of Las Palmas de Gran Canaria, Spain. He is the corresponding author and can be contacted at: gdiaz@dede.ulpgc.es

Asunción Beerli Palacio is professor of Marketing and Head of the Marketing Department at the University of Las Palmas de Gran Canaria. She is the author of ten books and has published more than one hundred articles and conference papers in the most prestigious Spanish and European marketing journals. She has advised, carried out research, and conducted executive seminars for a diverse set of organizations, including both nonprofit making and commercial business as well as several government agencies.

To purchase reprints of this article please e-mail: reprints@emeraldinsight.com Or visit our web site for further details: www.emeraldinsight.com/reprints 